\title{
Diagnostic and Therapeutic Stratagies in Maturity Onset Diabetes of the Young
}

\author{
Sofia Castro Oliveira ${ }^{1,2}$, Celestino Neves ${ }^{1,2}$, César Esteves ${ }^{1,2}$, Duarte Pignatelli ${ }^{1,2}$, Davide Carvalho ${ }^{1,2,3}$
}

${ }^{1}$ Department of Endocrinology, Diabetes and Metabolism of Centro Hospitalar de São João, Porto, Portugal; ${ }^{2}$ Faculty of Medicine, University of Porto, Portugal; ${ }^{3}$ Instituto de Investigação e Inovação em Saúde, University of Porto, Portugal

\section{BACKGROUND AND OBJECTIVE}

Maturity Onset Diabetes of the Young (MODY) has an estimated prevalence of 1-5\% in the diabetic population, but misdiagnosis as type 1 or type 2 diabetes is common. It comprises a heterogeneous group of monogenic diseases characterized by primary dysfunction of b-cell, young onset, autosomal dominant inheritance, without autoimmunity and without ketosis. Early diagnosis remains a challenge with important future implications, since it allows treatment optimization, prognosis definition and genetic counseling of family members.

OBJECTIVE: Characterize the parameters for the diagnosis of MODY.

\section{PATIENTS AND METHODS}

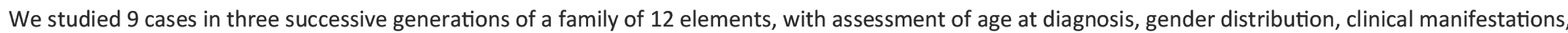

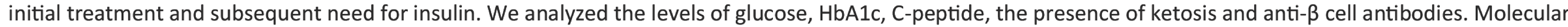

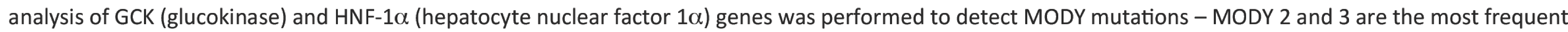
subtypes, accounting for $50-70 \%$ and $20-30 \%$ of cases, respectively $\Longrightarrow$ Institut de Biologie de Lille, Philippe Froguel

\section{RESULTS}

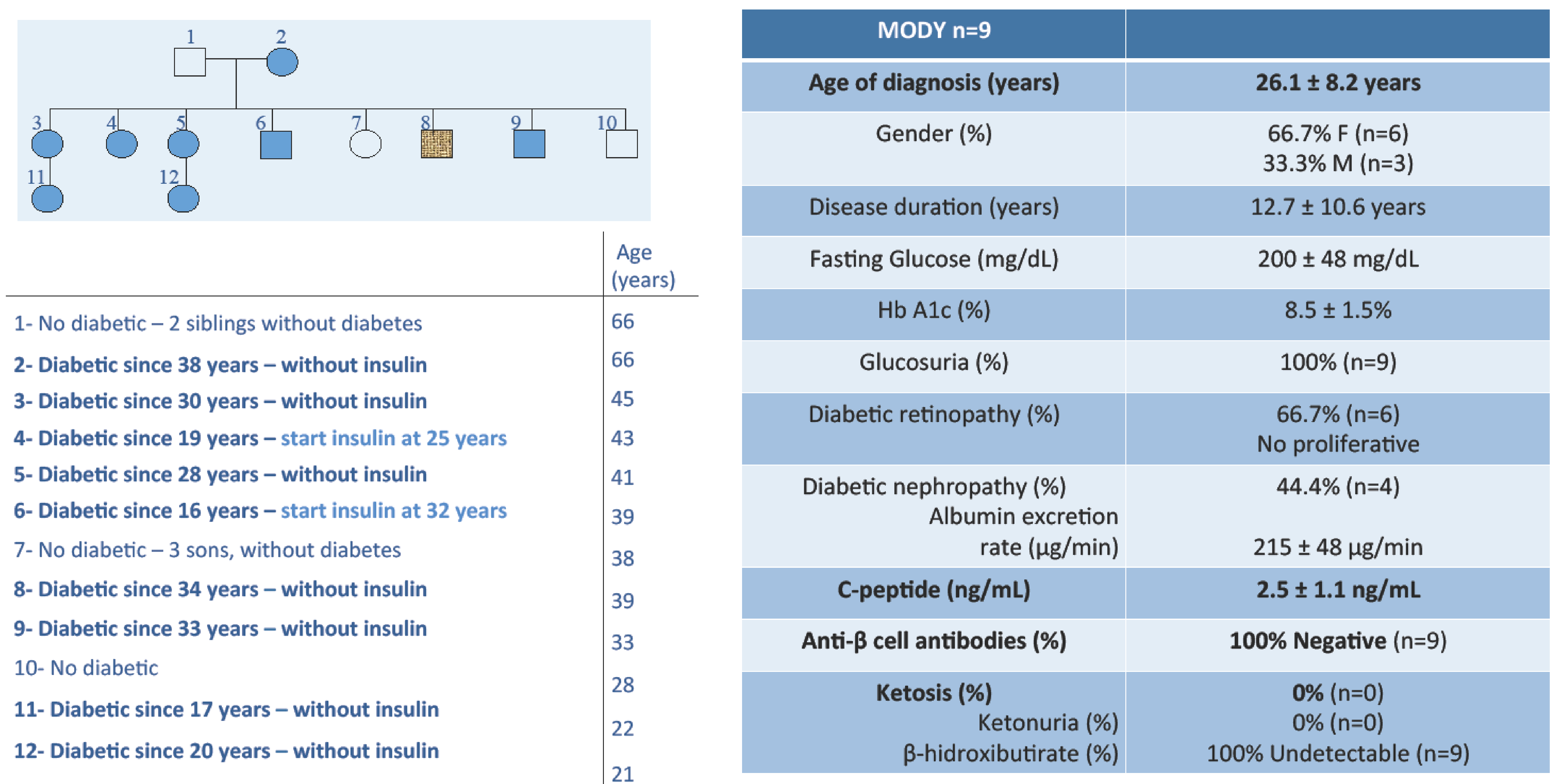

\begin{tabular}{|c|c|c|c|}
\hline Characteristics & MODY & DM1 & DM2 \\
\hline Age of diagnosis & $15-45$ years & $5-20$ years & $>25$ years \\
\hline Parental history & $60-90 \%$ & $<15 \%$ & $\begin{array}{c}10-40 \%(>50 \% \text { in } \\
\text { early onset } \\
\text { DM2) }\end{array}$ \\
\hline Heredity & $\begin{array}{l}\text { Autosomal } \\
\text { dominant }\end{array}$ & Polygenic & Polygenic \\
\hline Obesity & Uncommon & Uncommon & Common \\
\hline $\begin{array}{l}\text { Metabolic } \\
\text { Syndrome }\end{array}$ & Uncommon & Uncommon & Common \\
\hline $\begin{array}{c}\text { Insulin } \\
\text { Resistance }\end{array}$ & Uncommon & Uncommon & Common \\
\hline $\begin{array}{l}\text { Diabetic } \\
\text { Ketoacidosis }\end{array}$ & Rare & Common & Rare \\
\hline $\begin{array}{l}\text { Anti- } \beta \text { cell } \\
\text { Antibodies }\end{array}$ & Absent & Present & Absent \\
\hline C-Peptide & Normal & $\begin{array}{l}\text { No detectable/ } \\
\text { Low }\end{array}$ & Normal/High \\
\hline $\begin{array}{l}\text { First-line } \\
\text { Treatment }\end{array}$ & $\begin{array}{l}\text { Sulfonylurea } \\
\text { (MODY 1,3,4) } \\
\text { Diet (MODY 2) }\end{array}$ & Insulin & Metformin \\
\hline
\end{tabular}

Genetic testing revealed a mutation in exon 6 (stop mutation Ser 371 OCH) of gene HNF-1 $\alpha$ (MODY3)

Only 2 (22.2\%) patients, diagnosed at 16 and 19 years, required insulin therapy, at 32 and 25 years respectively. The remaining $7(77.8 \%)$ patients kept up with glibenclamide treatment (2.5-15mg/day).

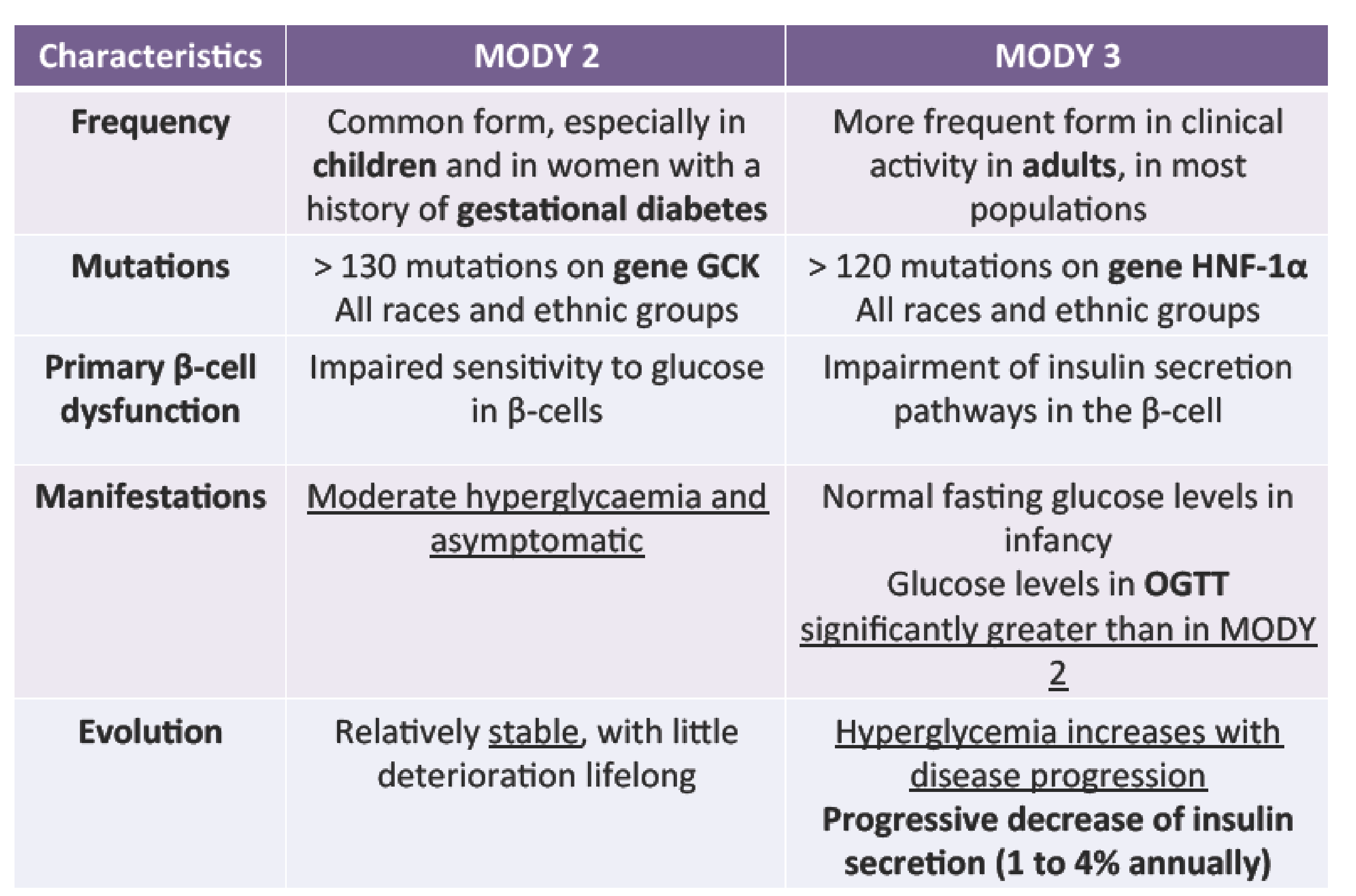

The 9 diabetics studied had clinical characteristics of MODY:

Asymptomatic hyperglycemia at early age; autosomal dominant transmission; several carriers of the disease in three generations of the same family

\begin{tabular}{|c|c|c|}
\hline Characteristics & MODY 2 & MODY 3 \\
\hline & $\begin{array}{l}\text { Good metabolic control only } \\
\text { with dietary measures }\end{array}$ & ADO ou insulin are needed \\
\hline $\begin{array}{l}\text { Insulin } \\
\text { requirement }\end{array}$ & $\begin{array}{l}\text { Exceptionally, some } \\
\text { individuals with severe } \\
\text { hyperglycemia require } \\
\text { insulin }(<2 \%)\end{array}$ & 30 to $40 \%$ require insulin \\
\hline $\begin{array}{c}\text { Chronic } \\
\text { complications }\end{array}$ & Rare & $\begin{array}{l}\text { Risk of microvascular } \\
\text { complications, particularly } \\
\text { retinopathy and nephropathy, } \\
\text { similar to DM1 and DM2 }\end{array}$ \\
\hline Particularities & & $\begin{array}{c}\text { Decreased renal reabsorption } \\
\text { of glucose and glycosuria } \\
\text { Marked sensitivity to insulin } \\
\text { secretagogues (sulfonylureas) }\end{array}$ \\
\hline
\end{tabular}

\section{CONCLUSION}

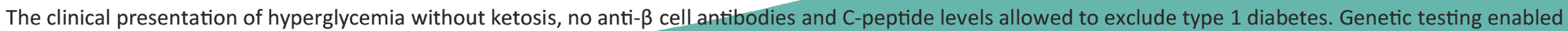
to confirm mutations in gene HNF-1a and guide treatment according to clinical evolution. 